\title{
Influence of the Bermuda High on interannual variability of summertime ozone in the Houston-Galveston-Brazoria region
}

\author{
Yuxuan Wang ${ }^{1,2}$, Beixi Jia ${ }^{2}$, Sing-Chun Wang ${ }^{1}$, Mark Estes ${ }^{3}$, Lu Shen ${ }^{4}$, and Yuanyu Xie ${ }^{2}$ \\ ${ }^{1}$ Department of Earth and Atmospheric Sciences, the University of Houston, Houston, TX, USA \\ ${ }^{2}$ Ministry of Education Key Laboratory for Earth System Modeling, Center for Earth System Science, \\ Tsinghua University, Beijing, China \\ ${ }^{3}$ Texas Commission on Environmental Quality, Austin, TX, USA \\ ${ }^{4}$ School of Engineering and Applied Sciences, Harvard University, Cambridge, MA, USA \\ Correspondence to: Yuxuan Wang (ywang246@ central.uh.edu)
}

Received: 7 July 2016 - Published in Atmos. Chem. Phys. Discuss.: 12 September 2016

Revised: 11 November 2016 - Accepted: 21 November 2016 - Published: 9 December 2016

\begin{abstract}
The Bermuda High (BH) quasi-permanent pressure system is the key large-scale circulation pattern influencing summertime weather over the eastern and southern US. Here we developed a multiple linear regression (MLR) model to characterize the effect of the $\mathrm{BH}$ on year-toyear changes in monthly-mean maximum daily $8 \mathrm{~h}$ average (MDA8) ozone in the Houston-Galveston-Brazoria (HGB) metropolitan region during June, July, and August (JJA). The $\mathrm{BH}$ indicators include the longitude of the $\mathrm{BH}$ western edge (BH-Lon) and the $\mathrm{BH}$ intensity index (BHI) defined as the pressure gradient along its western edge. Both $\mathrm{BH}-$ Lon and BHI are selected by MLR as significant predictors $(p<0.05)$ of the interannual (1990-2015) variability of the HGB-mean ozone throughout JJA, while local-scale meridional wind speed is selected as an additional predictor for August only. Local-scale temperature and zonal wind speed are not identified as important factors for any summer month. The best-fit MLR model can explain 61-72\% of the interannual variability of the HGB-mean summertime ozone over 1990-2015 and shows good performance in cross-validation ( $R^{2}$ higher than 0.48). The BH-Lon is the most important factor, which alone explains $38-48 \%$ of such variability. The location and strength of the Bermuda High appears to control whether or not low-ozone maritime air from the Gulf of Mexico can enter southeastern Texas and affect air quality. This mechanism also applies to other coastal urban regions along the Gulf Coast (e.g., New Orleans, LA, Mobile, AL, and Pensacola, FL), suggesting that the $\mathrm{BH}$ circulation pattern can
\end{abstract}

affect surface ozone variability through a large portion of the Gulf Coast.

\section{Introduction}

Surface ozone, as an important air pollutant, has significant adverse impacts on both public health and agriculture. Ozone is produced in the troposphere by photochemical oxidation of carbon monoxide (CO) and volatile organic carbon (VOCs), initiated by reaction with hydroxyl radicals $(\mathrm{OH})$ in the presence of nitrogen oxides $\left(\mathrm{NO}_{x}\right)$. Surface ozone is influenced not only by emissions of its precursors, but also by meteorological conditions (e.g., Jacob and Winner, 2009). Largescale circulation patterns can lead to local meteorological conditions that are favorable for ozone episodes, such as high temperatures, low wind speeds, clear skies, and stagnation (Nielsen-Gammon et al., 2005a; Ngan and Byun, 2011; Pearce et al., 2011; Psilogloue et al., 2013; Pugliese et al., 2014). Previous studies have demonstrated certain associations between large-scale circulations and surface ozone concentrations over the US (e.g., Darby, 2005; Rappenglück et al., 2008; Lin et al., 2012, 2015; Zhu and Liang, 2013; Shen et al., 2015). For example, surface ozone in the western US is affected by mid-latitude cyclones that transport Asian pollution eastward across the Pacific (Lin et al., 2012) and latespring stratospheric intrusions occurring more frequently following strong La Niña winters (Lin et al., 2015). In the Midwest and the northeastern US, polar jet frequency is a good 


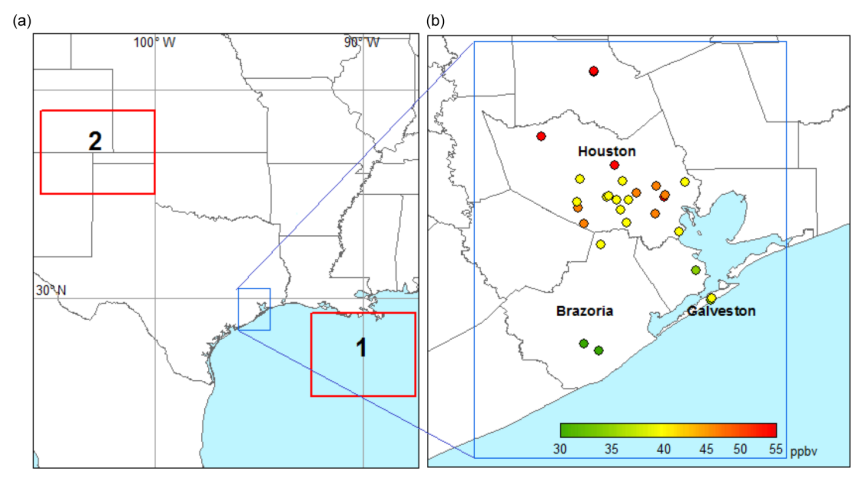

Figure 1. (a) Locations of the HGB region (blue box). The red boxes show the regions used to define the $\mathrm{BH}$ intensity indices $\mathrm{BHI}$; (b) locations of the CAMS sites within the HGB region and the long-term (1990-2015) mean MDA8 ozone from June to August.

indicator of the interannual variability of surface ozone in summer (Shen et al., 2015).

The Bermuda High (BH), a quasi-permanent system located over the North Atlantic Ocean (Davis et al., 1997), is the key large-scale circulation pattern that influences the regional climate over the eastern and southern US in summer (Li et al., 2012; Zhu and Liang, 2013; Hegarty et al., 2007; Hogrefe et al., 2004). The BH circulation pattern influences ozone air quality in the US through two mechanisms. First, as the BH shifts westward from late spring to summer, it places the eastern US under high pressures, resulting in meteorological conditions favorable for local production of ozone, such as high temperatures, clear skies, and stagnation. A number of studies have shown that high ozone concentrations easily occur over large parts of the northeast under the BH pressure pattern (Eder et al., 1993; Fiore et al., 2003; Hogrefe et al., 2004). Second, the southerly flows at the western edge of the $\mathrm{BH}$ bring clean marine air from the Gulf of Mexico to the southern Great Plains (Higgins et al., 1997). This maritime inflow has lower concentrations of ozone compared with the continental air it replaces, and is thus responsible for low ozone background over much of the Gulf States in summer (Langford et al., 2009; Ngan and Byun et al., 2011). These two mechanisms have been illustrated by Zhu and Liang (2013). Using observational data, they found positive correlations over the northeast between maximum daily $8 \mathrm{~h}$ average (MDA8) surface ozone in summer and the intensity of the $\mathrm{BH}$ on the interannual timescale due to the first mechanism, but negative correlations over the southerncentral US due to the second mechanism. Shen et al. (2015) further suggested that the location of the $\mathrm{BH}$ western edge has an influence on the summer mean MDA8 ozone in the southeast.

The Houston-Galveston-Brazoria (HGB) area is a major metropolitan area on the Gulf Coast located near the western edge of the BH in summer (Fig. 1). The HGB region was classified as a "marginal" nonattainment zone for ozone by the US Environmental Protection Agency (EPA) under the 2008 standard (TCEQ, 2012), although mean and peak ozone of the HGB area has decreased significantly during the past decades due to control of anthropogenic emissions (Berlin et al., 2013). A number of studies have demonstrated the importance of meteorology and circulation patterns on ozone over the HGB (Ngan et al., 2011; Rappenglück et al., 2008; Pakalapati et al., 2009; Haman et al., 2014), focusing predominantly on a typical year or episodic high ozone cases, such as those observed during the Texas Air Quality Study-II (Rappenglück et al., 2008; Day et al., 2009). Doppler lidar measurements of the strength and direction of the nocturnal low level jet (LLJ) during the TexAQS 2006 field campaign (Tucker et al., 2010) found a relationship between the nocturnal LLJ and ozone concentrations on the next day. A strong southerly nocturnal LLJ was linked to strong BH conditions due to the superposition of the sea breeze cycle on a strong synoptic-scale southerly flow. Given the evidence established by prior investigations on the overall influence of the BH on summertime ozone over the southern US (e.g., Zhu and Liang, 2013; Shen et al., 2015), we hypothesize that the large-scale circulation patterns associated with the BH play a key role in driving the year-to-year change in surface ozone over the HGB. In this study we will test this hypothesis by examining the statistical relationship between the variability of the BH and MDA8 ozone over the HGB during June, July, and August (JJA), a time period when the BH is located closer to North America and exerts large influences on circulation patterns over the HGB.

\section{Data and methods}

\subsection{Ozone observations}

The HGB region is delineated by longitude from -94.5 to $-96.0^{\circ} \mathrm{W}$, and by latitude from 28.5 to $30.5^{\circ} \mathrm{N}$ (blue box in Fig. 1a). Surface ozone concentrations over the HGB have been routinely monitored at continuous ambient monitoring stations (CAMSs) maintained by the Texas Commission on Environmental Quality (TCEQ), the City of Houston, and Harris County. Observational records of surface ozone in JJA from 1990 to 2015 were obtained from the EPA AirData website (http://www3.epa.gov/airquality/ airdata/ad_data_daily.html). Ozone observations from 28 ozone CAMS sites in the HGB region that have data records longer than 10 years were used for analysis. Figure $1 \mathrm{~b}$ displays the site distributions and long-term mean ozone in JJA at each site. The site locations and operation time periods are provided in Table S1 in the Supplement. The number of CAMS sites increases to 16 in 1998 and 21 in 2004. There are eight sites with continuous observations from 1990 to the present. The overall data coverage at each selected site is $99 \%$ during its operation period, except for the Houston East site that has ozone observations since 1990 but no data 

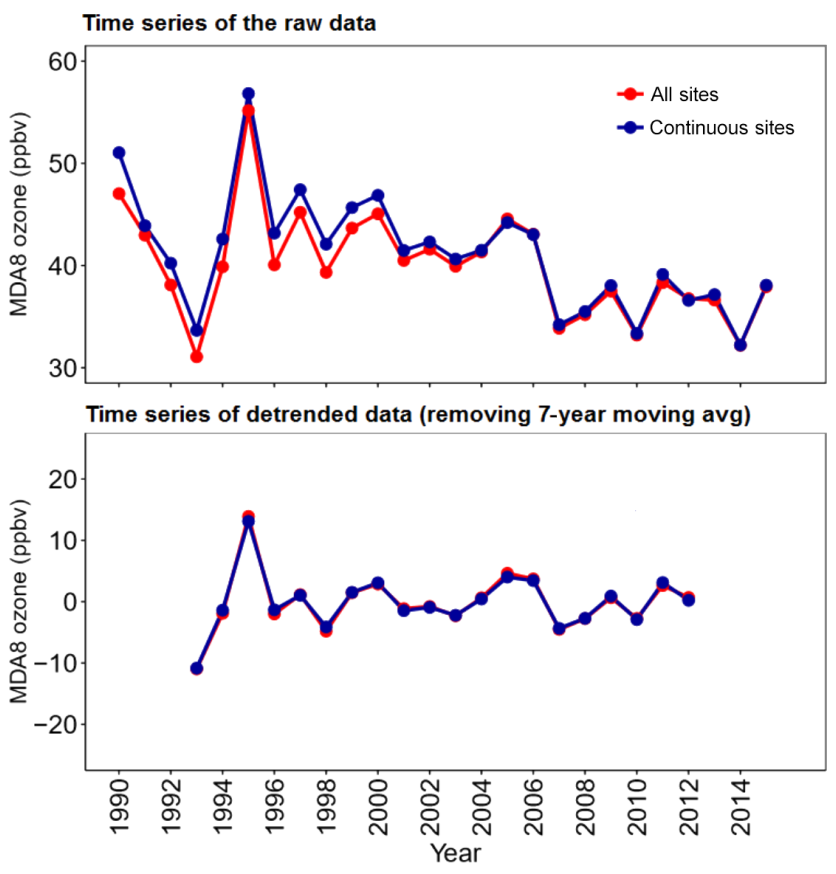

Figure 2. Summer (JJA)-mean ozone over the HGB area during the period from 1990 to 2015 . The upper panel is the time series of the raw data and the lower panel is the detrended time series after subtracting the 7-year moving averages. The red line is the average from all available sites for each year and the blue line is the average of those sites with continuous coverage from 1990 to 2015.

during 1993-1995. In what follows, all the ozone data and related discussions are MDA8 ozone and the correlation coefficient, $r$, reported in this study is the Pearson correlation coefficient unless stated otherwise.

As shown in Fig. 1b, the sites in Galveston and Brazoria counties have lower ozone concentrations than the sites in the Houston region, due in part to lower local emissions. Since the scope is synoptic-scale circulation patterns, we focus on the HGB-mean ozone rather than ozone at individual sites. To calculate the HGB-mean ozone for a given month, we averaged ozone observations from all eligible sites (all-site average) and compared that with the average of only those sites with continuous observations since 1990 (continuoussite average). The difference in the HGB-mean ozone calculated from the two averaging approaches is within $5 \mathrm{ppbv}$ and diminishes in the 2000s as the sites' number increases (Fig. 2a). To remove the influence of the decreasing trend in anthropogenic emissions on the interannual variability of ozone, the HGB-mean ozone of each month (JJA) was detrended by subtracting the 7-year moving average of the corresponding month. The de-trending process further decreases the difference in the HGB-mean ozone calculated from the two averaging approaches (Fig. 2b). Therefore we use the all-site average to present the HGB-mean ozone. The time series of the de-trended HGB-mean ozone is from 1993 to 2012.

\subsection{Meteorological data}

The meteorological data consist of the geopotential height at $850 \mathrm{hPa}$ and sea level pressure (SLP) from the National Centers for Environmental Prediction (NCEP) Reanalysis 1 with a spatial resolution of $2.5^{\circ} \times 2.5^{\circ}$ (Kalnay et al., 1996), which were used to derive the $\mathrm{BH}$ indices described below. We adopted $2 \mathrm{~m}$ temperature $(T)$, zonal $(U)$, and meridional $(V)$ components of wind at $850 \mathrm{hPa}$ from the European Centre for Medium-Range Weather Forecasts (ECMWF) Interim reanalysis with a finer spatial resolution of $0.5^{\circ} \times 0.5^{\circ}$. These data were used to calculate the local-scale meteorological parameters, including the $\mathrm{HGB}$-mean temperature and $850 \mathrm{hPa}$ winds $(U$ and $V)$.

\subsection{BH indices}

Figure 3 illustrates the mean $\mathrm{BH}$ circulation patterns from June to August. The HGB region is located to the west of the $\mathrm{BH}$, and is thus under strong southerly winds from June to August. The intensity of the BH peaks in July. As the BH intensifies from June to July, its western edge moves westward toward the North American continent; when it weakens from July to August, its western edge retreats eastward away from the continent. Separate indices have been used to define the intensity and location of the BH (Stahle and Cleaveland, 1992; Ortegren et al., 2011; Li et al., 2011; Zhu and Liang, 2013). For the BH location, we adopted the BH longitudinal index (BH-Lon) from Li et al. (2011) as a measure of the westward extension of the BH. They defined the BH-Lon as the longitude of the cross-point of the 1560 geopotential meter $(\mathrm{gpm})$ isoline and the $850 \mathrm{hPa}$ wind ridgeline. The wind ridgeline refers to the roughly zonal line that separates the easterly trade winds in the south from the westerly winds in the north, and it can be written mathematically as $u=0$ and $\frac{\partial u}{\partial y} \geq 0$, where $u$ is the zonal wind component and $y$ is the meridional coordinate. The location of the $1560 \mathrm{gpm}$ isoline is linearly interpolated to the precision of $0.1^{\circ}$ from the gridded reanalysis data. The BH-Lon is always negative in longitude, thus with more negative values, meaning closer proximity to Houston.

The intra-seasonal variability of the BH (cf. Fig. 3) will affect the value of BH-Lon when defined with reference to a fixed isoline. For instance, the $1560 \mathrm{gpm}$ isoline is located further away from the HGB in August when the BH is weaker than in July, even when the center location of the BH from the HGB does not change between the two months. To reduce such an effect, we tried different isolines with an interval of $4 \mathrm{gpm}$ from 1560 to $1536 \mathrm{gpm}$ in the calculation of the $\mathrm{BH}-$ Lon by month and evaluated which definition captures the most variability of the HGB-mean ozone. For June and July, the BH-Lon is best defined on the basis of the $1560 \mathrm{gpm}$ isoline, the same as in Li et al. (2011), and this definition results in the interannual (1993-2012) correlation $(r)$ of 0.69 between detrended BH-Lon and HGB-mean ozone. The BH- 


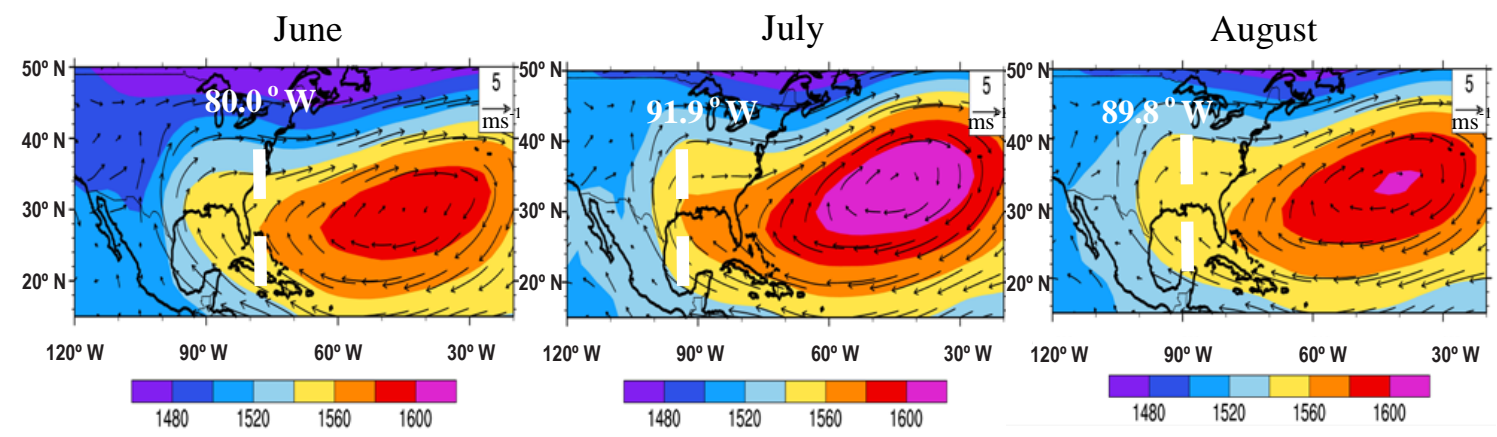

Figure 3. Distributions of the 1998-2013 mean $850 \mathrm{hPa}$ geopotential height (color contour) and wind fields (arrows; $\mathrm{m} \mathrm{s}^{-1}$ ) in June (left), July (center), and August (right). The thick white dashed line shows the longitude of the BH-Lon (values shown in white).
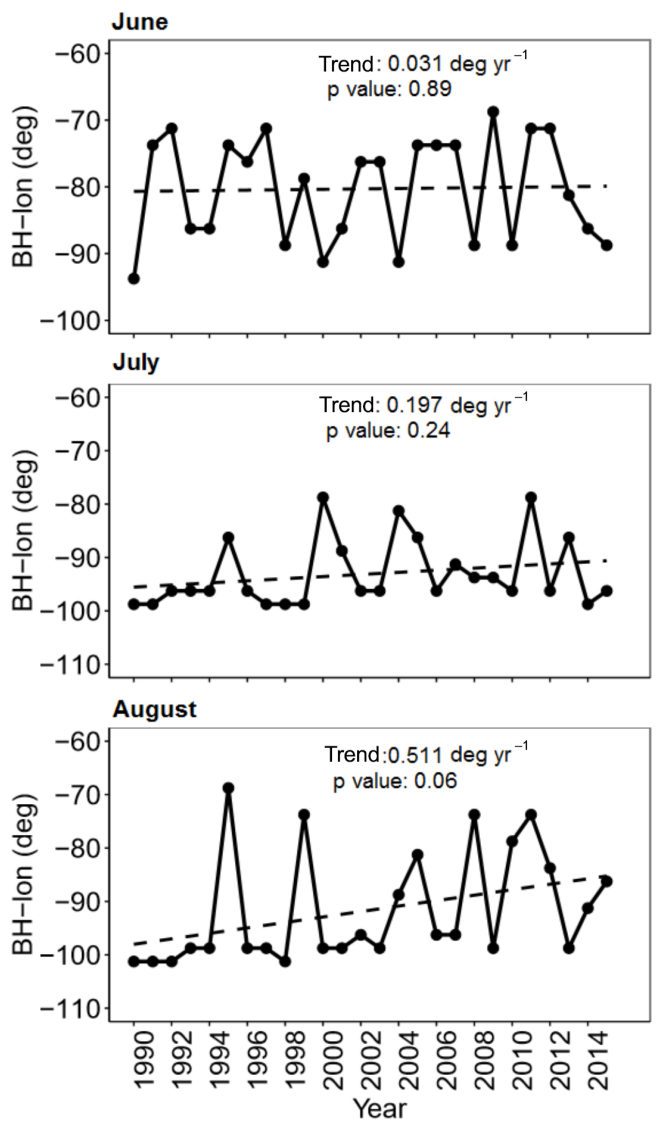

Figure 4. Time series of the BH-Lon (solid line) in June, July, and August from 1990 to 2015. A linear trend (dashed line) is used to fit each time series.

Lon for August is defined using the $1556 \mathrm{gpm}$ and the corresponding $r$ is 0.62 .

The time series of monthly-mean BH-Lon is shown in Fig. 4. In correspondence to the intra-seasonal movement of the $\mathrm{BH}$ shown in Fig. 3, the mean value of BH-Lon from 1990 to 2015 was $80.3^{\circ} \mathrm{W}$ in June, $93.1^{\circ} \mathrm{W}$ in July, and $91.6^{\circ} \mathrm{W}$ in August. There were no significant trends in BH-
Lon for the months of June and July. In August, however, $\mathrm{BH}-$ Lon exhibited a significant increasing trend (i.e., an eastward shift) of $0.51^{\circ} \mathrm{a}^{-1}(p<0.1)$ over 1990-2015, but this trend becomes insignificant if the first 4 years (1990-1993) were excluded. Shen et al. (2015) found an increasing trend of $0.35^{\circ} \mathrm{a}^{-1}$ in the JJA-mean BH-Lon over 1980-2010 using the definition of $\mathrm{Li}$ et al. (2011). Rather than a change in the $\mathrm{BH}$ circulation patterns, they attributed this trend to a spatially uniform decrease in SLP over the US and the adjacent Atlantic Ocean in the reanalysis data. Given their work as well as the lack of a consistent trend in the monthly-mean BH-Lon over 1990-2015, we do not consider the trend of $\mathrm{BH}-\mathrm{L}$ on in the present work. To be consistent with the ozone data, the BH-Lon time series were processed by removing the 7-year moving averages.

Another type of $\mathrm{BH}$ index is defined on the basis of pressure differences between two representative locations, with their exact locations varying among studies. Zhu and Liang (2013) defined a pressure-based BH index (BHI) as the mean SLP difference between a location in the Gulf of Mexico and the other in the southern Great Plains where the SLP has the largest positive and negative correlation with LLJ, respectively. As a result, their BHI exhibits a significant positive association with the strength of LLJ, which determines the transport of clean marine air from the Gulf of Mexico. Similar to that study, we defined a pressure-based BHI as the mean SLP difference along the western edge of the BH, between the same location in the southern Great Plains (35$39^{\circ} \mathrm{N}, 105.5-100^{\circ} \mathrm{W}$ ) as selected by Zhu and Liang (2013) (box 2 in Fig. 1a) and the other in the Gulf of Mexico (25.3$29.3^{\circ} \mathrm{N}, 92.5-87.5^{\circ} \mathrm{W}$; box 1 in Fig. 1a) where the SLP exhibits the largest correlation with the HGB-mean ozone. Our Gulf of Mexico domain is located $2.5^{\circ}$ east of that defined by Zhu and Liang (2013). This BHI shows only weak to moderate correlations with BH-Lon, with $r$ being $-0.57,-0.26$, and -0.39 for JJA, respectively, suggesting the position of the BH western edge may not vary coherently with the pressure gradient over the western edge. Therefore, both BH-Lon and $\mathrm{BHI}$ are used as predictors in the regression model described below. 


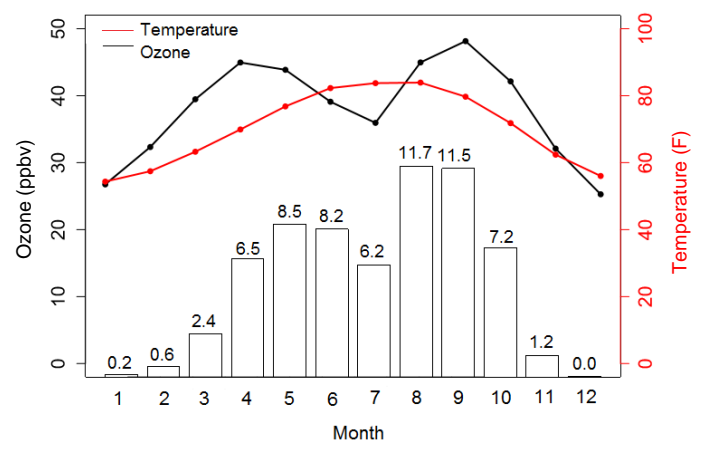

Figure 5. The 1990-2015 mean monthly MDA8 ozone over the HGB area (black line), overlaid with the average number of exceedance days by month (bars) and the HGB-mean temperature (red line). An exceedance day is defined when MDA8 ozone at one or more monitors in HGB is higher than 70 ppbv.

\subsection{Statistical method}

We applied a multiple linear regression (MLR) model, which has been commonly used in air quality and meteorological studies (e.g., Kutner et al., 2004; Tai et al., 2010), to construct the statistical relationship between the detrended HGB-mean ozone and the five meteorological predictors described above, including BH-Lon, BHI, $T, U$, and $V$. Since our focus is on variability, all the meteorological predictors were detrended using the same approach as the ozone data. For ease of comparison, all the meteorological predictors in the regression analysis were normalized. The regression was conducted on the monthly scale from 1993 to 2012. The model is of the form

$y=\beta_{0}+\sum_{k=1}^{n} \beta_{k} \chi_{k}$,

where $y$ is the detrended monthly HGB-mean MDA8 $\mathrm{O}_{3}, n$ is the number of predictors, $\chi_{k}$ represents the $k$ th predictor which is detrended and normalized, $\beta_{k}$ is the corresponding regression coefficient for $\chi_{k}$, and $\beta_{0}$ is the intercept. The predictors are separated into two groups. We applied a stepwise regression using the $\mathrm{BH}$ indices (BH-Lon, BHI) first, which represent the large-scale effects. The HGB-mean $T$, $U$, and $V$ that characterize local meteorological conditions were added subsequently only if they result in significant improvements in model performance. The predictor selection is based on the Akaike information criterion (AIC) statistics to obtain the best model fit (Venables and Ripley, 2003).

\section{Results}

\subsection{Ozone and the $\mathrm{BH}$ relationship}

The HGB-mean ozone shows a large intra-seasonal variation during JJA (Fig. 5), with a minimum of monthly-mean ozone in July. We first examined whether this feature can be explained by near-surface temperature, which has been suggested as an important meteorological factor affecting surface ozone in many regions (Fu et al., 2015; Rasmussen et al., 2012; Camalier et al., 2007). As shown in Fig. 5, the HGBmean temperature is the highest in July when the monthlymean ozone is lowest, precluding temperature as the driver of the intra-summer variability of ozone over the HGB region. This can be explained by the fact that summertime temperatures over the HGB region are always high; thus, the temperature variation is relatively less significant and the ozone formation might not be limited by temperature over this region in summer. To further support this argument, on the interannual timescale (1993-2012) the HGB-mean ozone shows no correlation with temperature in June $(r=-0.14)$, although the correlation coefficient between the two increases to 0.29 and 0.41 in July and August, respectively.

The BH-Lon reaches its westernmost location in July (Fig. 3), coincident with the ozone minimum (monthly mean) in the same month. This coincidence supports the mechanism that the more westward shift of the BH (the lower BH-Lon) brings the stronger inflow of cleaner maritime air into the HGB, leading to lower surface ozone. The decrease in background ozone over the HGB region from spring to summer is reported by a number of observational and modeling studies (Nielsen-Gammon et al., 2005a, b; Li et al., 2002; Reidmiller et al., 2009) and can be attributed to strengthening of this maritime inflow in summer. Indeed, the BH-Lon shows a significantly stronger correlation with the HGB-mean ozone during JJA $(r=0.64-0.74)$ than temperature does. However, the BH-Lon does not correlate well with the HGB-mean temperature, with $r$ being $-0.04,0.44$, and 0.33 for JJA, respectively. The BH-Lon has a higher correlation with the HGBmean meridional wind $(V ; r=-0.4-0.7)$ but does not correlate with the zonal wind $(U)$. This is expected because the $\mathrm{BH}$ determines the strength of the meridional flows that bring maritime air masses from the Gulf of Mexico to southeastern Texas.

Considering the large intra-summer variation in ozone, $\mathrm{BH}-\mathrm{Lon}$, and their association, the effects of the $\mathrm{BH}$ on the HGB-mean ozone are analyzed month by month in the following sections. For comparison, Zhu and Liang (2013) combined the intra-seasonal and interannual variations of ozone and Shen et al. (2015) focused on the variability of the JJAmean ozone. Both studies investigated the southern US as a whole. We note here that HGB ozone exhibits a bimodal seasonality (cf. Fig. 5), with $41 \%$ of exceedance days occurring in JJA, and the rest in the spring and early fall. The meteorological features identified here are not expected to predict peak ozone outside of JJA, which is a limitation of the study.

\subsection{Statistical model}

Using the stepwise regression (Eq. 1), we obtained the bestfit MLR equations for the interannual variability of the HGB- 
Table 1. Regression coefficients and coefficients of determination $\left(R^{2}\right)$ of the best-fit MLR models for June, July, and August. The model cross-validation $R^{2}$ is shown in the last column.

\begin{tabular}{lrrrrrrr}
\hline & $\begin{array}{r}\beta_{0} \\
\text { (intercept) }\end{array}$ & BH-Lon & BHI & $V$ & $R^{2}$ & $\begin{array}{r}\text { Adjusted } \\
R^{2}\end{array}$ & $\begin{array}{r}\text { Cross-validation } \\
R^{2}\end{array}$ \\
\hline June & 0.16 & 4.52 & -3.84 & - & 0.61 & 0.56 & 0.48 \\
July & -0.26 & 3.44 & -2.98 & - & 0.72 & 0.69 & 0.59 \\
August & -0.14 & 3.34 & 3.21 & -5.21 & 0.70 & 0.64 & 0.51 \\
\hline
\end{tabular}
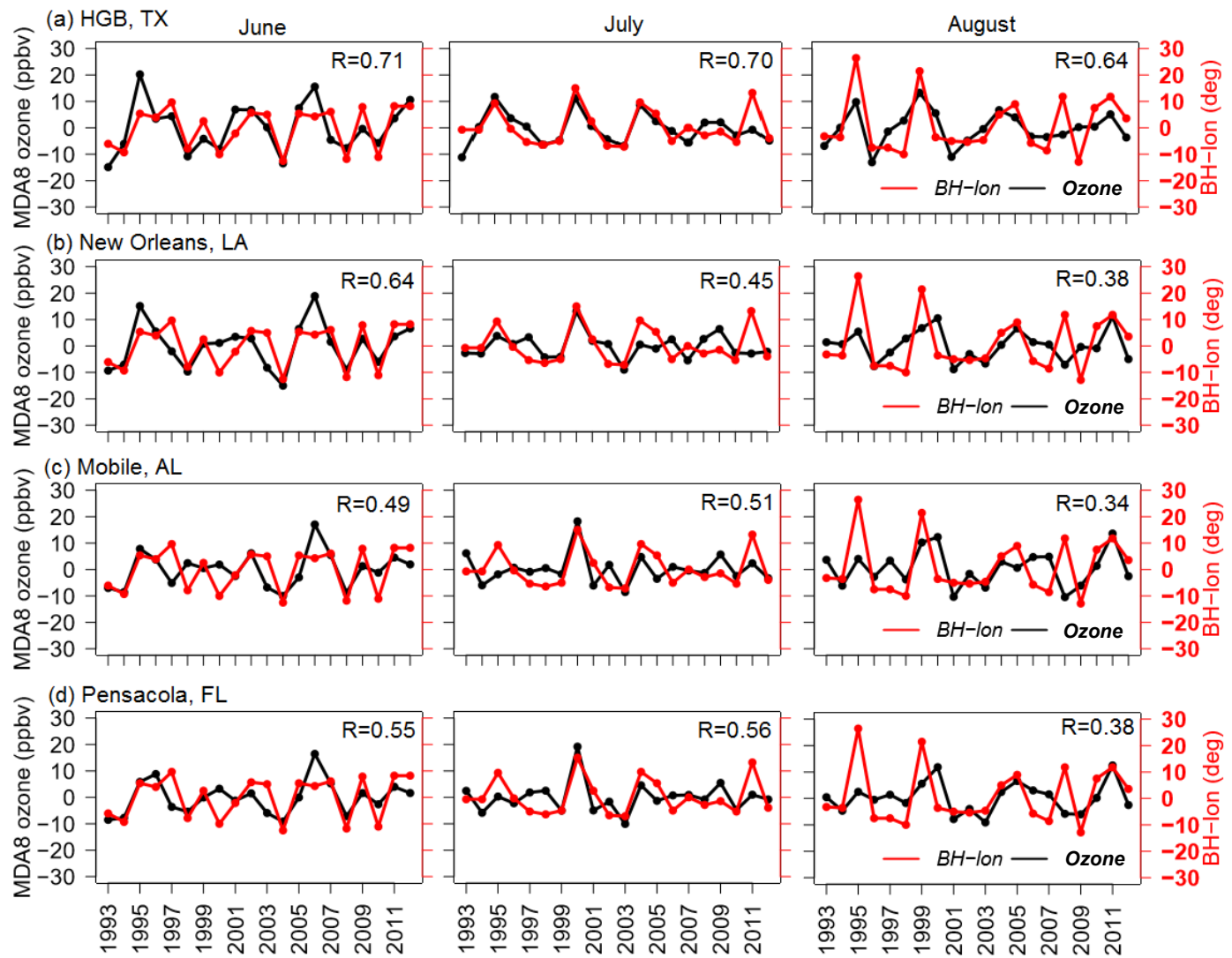

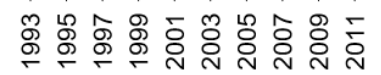

Figure 6. The time series of detrended BH-Lon (red line) and MDA8 ozone (black line) during June, July, and August over the HGB region, TX (a), New Orleans, LA (b), Mobile, AL (c), and Pensacola, FL (d). The correlation coefficients between BH-Lon and ozone are shown in each figure.

mean ozone by month. Table 1 summarizes the regression results, including the predictors selected for each month and their regression coefficients. Both BH-Lon and BHI are selected as significant predictors $(p<0.05)$ for each month, while $V$ is selected as an additional predictor for August only. Temperature is not selected as a predictor by the MLR for any month, which is consistent with insignificant correlation between ozone and temperature presented above. The HGB-mean zonal wind $(U)$ is not selected for any month either. The coefficients of determination $\left(r^{2}\right)$ from the MLR are 0.61 for June, 0.72 for July, and 0.70 for August.

We verified that the MLR model results are not sensitive to the data de-trending methods (Table S2 in the Supple- ment). The use of raw ozone data significantly degrades the model performance because ozone has a significant decreasing trend driven by declining emissions, a factor not included in the MLR. If only raw BH-Lon data are used, $R^{2}$ values decrease only slightly $(<10 \%)$. If both ozone and meteorological variables are linearly de-trended, $R^{2}$ values are about $20 \%$ lower but are still all higher than 0.5 . We further tested that $V$ is a robust predictor in the MLR model for August (Table S3). The $R^{2}$ values decrease substantially if $V$ is removed from the MLR, and this change is not affected by the de-trending methods.

Figure 7 displays the time series of the observed and MLRregressed monthly-mean ozone (both detrended) from 1993 


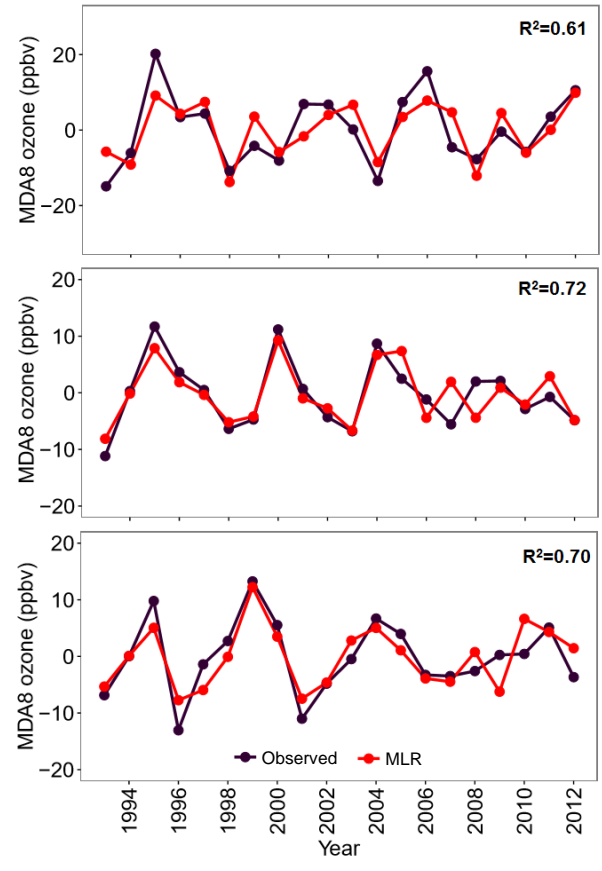

Figure 7. Time series of observed HGB-mean MDA8 ozone (black line) and MLR-regressed ozone (red line) in June (top), July (middle), and August (bottom). The data presented are detrended.

to 2012. Many of the extremely high and low ozone months are reproduced well by the MLR model, for example, the low ozone month of June 2004 and high ozone month of August 2011. The BH-Lon is the most important predictor throughout JJA and has the highest regression coefficient (absolute values) that is positive throughout JJA (Table 1). Given the BH-Lon being negative, this means that as the Bermuda High extends more westward, ozone over the HGB is lowered, which supports the hypothesis that the $\mathrm{BH}$ brings maritime inflow of low ozone background into the HGB region. The MLR relationship indicates that monthly-mean MDA8 ozone over the HGB area will decrease by $4.52,3.44$, and $3.34 \mathrm{ppbv}$, respectively, for every degree of westward extension of the BH-Lon in June, July, and August.

While the MLR model developed here captures 61-72\% (based on $R^{2}$ ) of the interannual variance of the HGB-mean ozone from June to August, the meteorological predictors may be correlated with each other, leading to overfitting of the data. To examine the multi-collinearity between the meteorological predictors, the variance inflation factor (VIF), a widely used index of the collinearity in the regression analysis, was calculated for each variable. Table 2 summarizes the VIF of each predictor by month. Most of the VIFs are smaller than 3, much lower than the commonly used VIF threshold of 10 in determining significant collinearity (Kutner et al., 2004), indicating that the problem of multi-collinearity among the predictors is generally unimportant.

\subsection{Model cross-validation}

The MLR model described above shows good regression performance in explaining the interannual variations of the summertime HGB-mean ozone on the monthly scale. To evaluate the predictability of this model, a cross-validation $(\mathrm{CV})$ method was implemented. We first isolated one year at a time, performed model fitting with the remaining years, and then applied the model to predict the monthly-mean ozone on the isolated year. Figure S1 in the Supplement shows the $\mathrm{CV}$ results by month. The $R^{2}$ between the observed and $\mathrm{CV}$-predicted ozone is $0.48-0.59$, indicating that the MLR model is capable of predicting about $50 \%$ interannual (19932012) variability of monthly-mean ozone over the HGB area in summer. However, some of the extreme ozone values are not well predicted, suggesting that other factors are responsible for those high ozone events, e.g., emissions and stagnation conditions, which are not considered as predictors in the MLR model.

\section{Discussion}

\subsection{Comparison with other studies}

To the best of our knowledge, the MLR correlation coefficients $(r=0.78-0.84)$ are significantly higher than those from previously published studies on the regression relationship between interannual variability of meteorological factors and surface ozone over a metropolitan region or the southern US as a whole. Zhu and Liang (2013) reported a negative correlation of -0.5 to -0.7 between the BHI and summer-mean MDA8 ozone over the southern Great Plains (including Houston) during 1993-2010. Shen et al. (2015) identified the polar jet, the Great Plains low-level jet, and the $\mathrm{BH}$ as major synoptic-scale patterns influencing surface $\mathrm{O}_{3}$ variability in the eastern US in summer, which in combination explain $53 \%(r=0.73)$ of the interannual variance of summer-mean MDA8 ozone in the southern central US during 1980-2010. These studies averaged surface ozone over a large geographical region and onto a seasonal mean and thus smoothed out some variability. By comparison, the present study investigates the interannual variability of monthly-mean ozone over a smaller region (HGB) and extends to more recent time periods (1990-2015). With just three meteorological predictors (BH-Lon, BHI, and $V$ ), the MLR model developed here captures $61-72 \%$ of the interannual variance of the HGB-mean ozone during JJA. The MLR model developed here shows a good prediction skill with the CV $R^{2}$ higher than 0.48 for each month of JJA.

\subsection{Mechanism}

Among the meteorological predictors examined here, indicators of the BH location (BH-Lon) and strength (BHI) explain more interannual variability of the summertime HGB- 

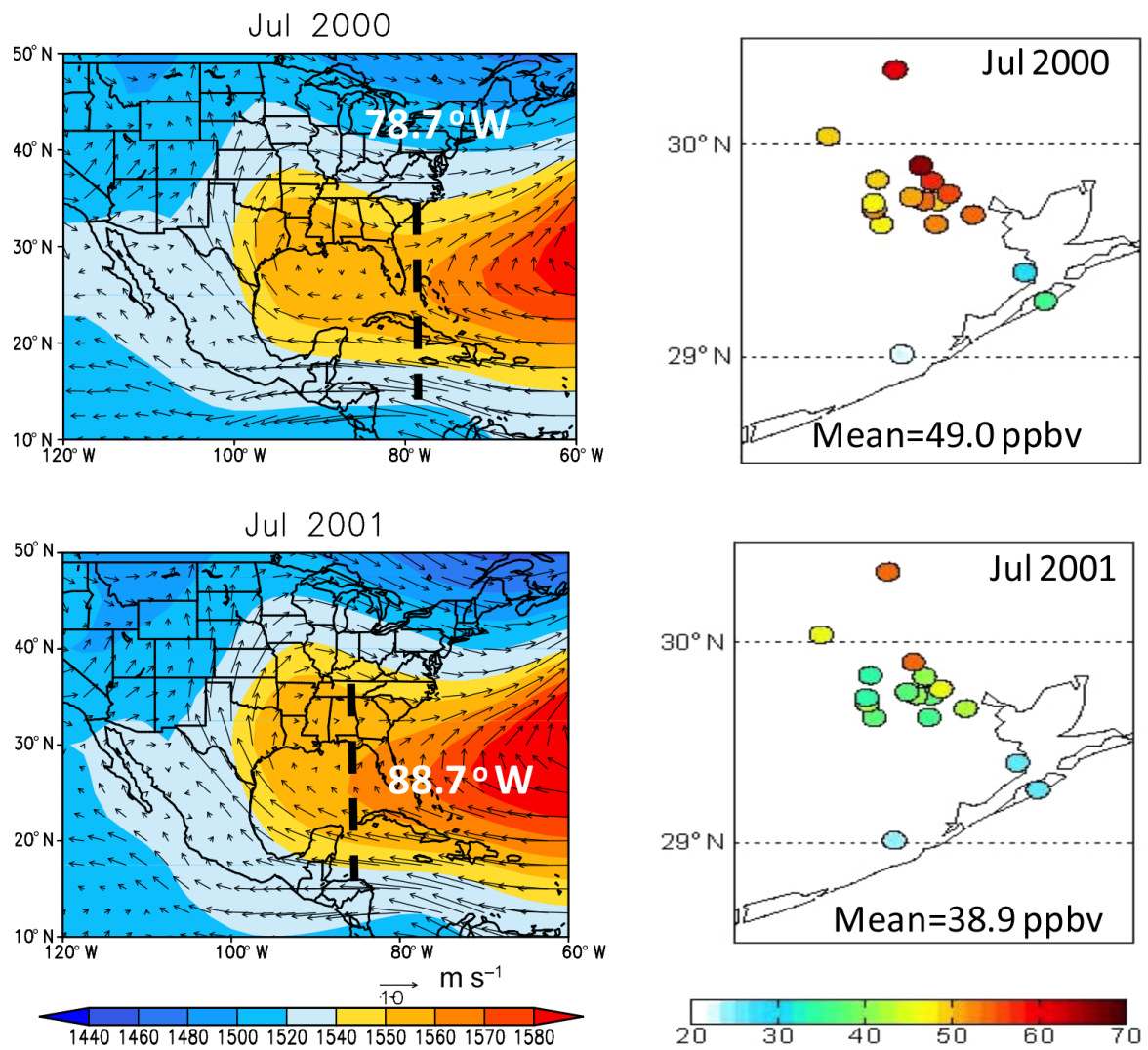

ppbv

Figure 8. (Left) $850 \mathrm{hPa}$ geopotential height (gpm) and wind field $\left(\mathrm{m} \mathrm{s}^{-1}\right)$ for the months July 2000 and July 2001 . The black dashed line shows the longitude of the BH-Lon (values shown in white). (Right) MDA8 ozone concentrations at the CAMS sites in HGB for July 2000 and July 2001.

(a) Jul 2011

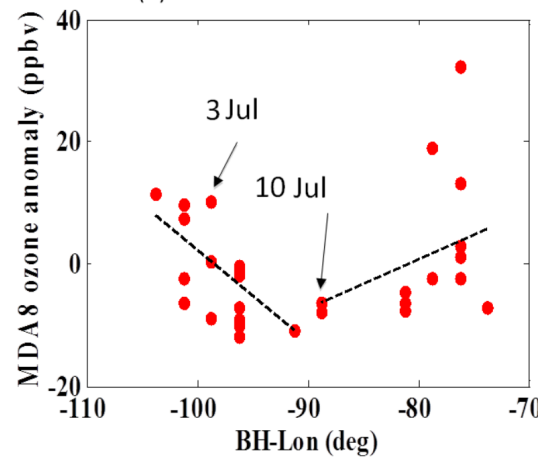

(b) 3 Jul 2011

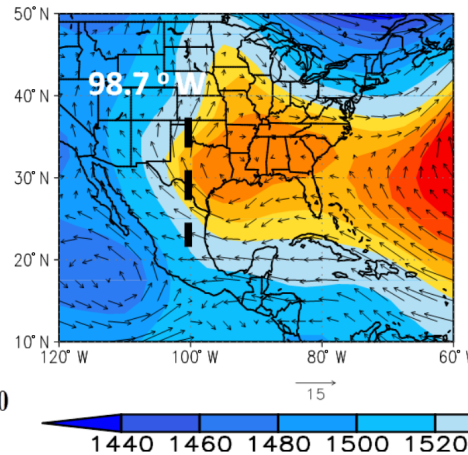

(c) $10 \mathrm{Jul} 2011$

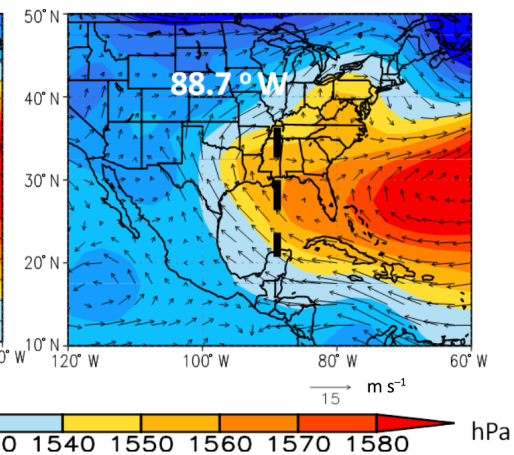

Figure 9. (a) Relationship between daily ozone anomaly ( $y$ axis) and daily BH-Lon ( $y$ axis) for July 2011. (b-c) Distribution of SLP (color contours) and $850 \mathrm{hPa}$ wind fields (arrows) on 3 July (b) and 10 July 2011 (c). The black dashed line shows the longitude of the BH-Lon (values shown in white).

mean ozone than local meteorological factors (i.e., winds and temperature), indicating the dominant role of large-scale circulation patterns controlling ozone variability over this region in summer. The BH-Lon is the most important predictor throughout JJA, which alone explains 38-48\% of the observed interannual variability of monthly-mean ozone over the HGB region. As discussed above, the $\mathrm{BH}$ circulation pat- terns in summer are responsible for the inflow of low ozone air masses from the Gulf of Mexico into the HGB region. The MLR results suggest that the $\mathrm{BH}$-Lon is a better predictor than local-scale meridional wind to indicate the variability of this maritime inflow and consequently surface ozone.

As a further illustration of this mechanism, Fig. 8 compares circulation patterns and associated changes in the 
Table 2. Variance inflation factor (VIF) of the predictors selected in the MLR mode for June, July, and August.

\begin{tabular}{lrrr}
\hline & BH-Lon & BHI & $V$ \\
\hline June & 1.47 & 1.47 & - \\
July & 1.07 & 1.07 & - \\
August & 1.21 & 2.21 & 2.22 \\
\hline
\end{tabular}

HGB-mean ozone between two representative months, July 2000 and July 2001. The BH was not only stronger in July 2001, but also extended closer to the southeastern US during that month than July 2000 . The BH-Lon was $88.7^{\circ} \mathrm{W}$ in July 2001 as compared to that of $78.7^{\circ} \mathrm{W}$ in July 2000 , indicating stronger maritime influence on HGB during July 2001. Correspondingly, surface ozone concentrations were significantly lower at all the CAMS monitors during July 2001 than July 2000 (Fig. 8). The HGB-mean ozone was 38.9 ppbv in July 2001, compared with 49.0 ppbv in July 2000. The number of ozone nonattainment days was also lower in July 2001 (2 days) than July 2000 (6 days). Despite different BHLon, the HGB-mean $V$ happened to be the same during the two months, both $-2.1 \mathrm{~m} \mathrm{~s}^{-1}$. This indicates that local-scale wind alone may not be sufficient to indicate the origin of air masses because winds are affected by both large-scale and local-scale factors.

Given the large-scale influence of the $\mathrm{BH}$, the mechanism underlying the $\mathrm{BH}$ and $\mathrm{O}_{3}$ association over the $\mathrm{HGB}$ region, if correct, should apply for other urban regions along the Gulf Coast which experience similar onshore maritime flow from the Gulf of the Mexico in summer. To test this, we chose New Orleans in Louisiana $\left(29.8-30.6^{\circ} \mathrm{N}, 89.9-90.7^{\circ} \mathrm{W}\right)$, Mobile in Alabama (30.4-30.8 $\left.\mathrm{N}, 88.0-88.2^{\circ} \mathrm{W}\right)$, and Pensacola in Florida $\left(30.3-30.5^{\circ} \mathrm{N}, 87.2-87.3^{\circ} \mathrm{W}\right)$, all of which are at about $30^{\circ}$ latitude, similar to HGB. Figure $6 \mathrm{~b}-\mathrm{d}$ present the time series of surface ozone (detrended and averaged over all the CAMS monitors) at these urban areas during JJA along with BH-Lon. On interannual timescales (1993-2013), monthly-mean ozone concentrations at the three urban regions all exhibit significantly positive correlations with the BH-Lon throughout JJA ( $r=0.38-0.64)$, which is consistent with the $\mathrm{BH}-\mathrm{O}_{3}$ association over $\mathrm{HGB}$ and thus confirms the large-scale impact of the $\mathrm{BH}$ circulation patterns on surface ozone variability along the Gulf Coast. It is interesting to note that the $\mathrm{BH}-\mathrm{O}_{3}$ correlation coefficients at $\mathrm{HGB}$ are highest among the four urban regions along the Gulf Coast. This can be partly explained by the fact that HGB has the largest quantity of ozone-precursor emissions among the four urban areas, so that the intrusion of clean maritime air masses would cause a larger relative reduction of ozone at HGB, and therefore the BH location and strength could cause more ozone variability.

\subsection{Threshold value of BH-Lon}

Shen et al. (2015) identified a threshold value of $85.4^{\circ} \mathrm{W}$ for the JJA-mean BH-Lon that marks two different associations of the BH-Lon with surface ozone in the eastern US. When the BH-Lon is east of $85.4^{\circ} \mathrm{W}$, westward movement of the BH-Lon leads to a decrease in surface ozone; when it is west of that threshold, its westward movement leads to an increase in ozone. We did not find such a threshold value of BH-Lon for the monthly scale analysis presented above; the monthlymean relationship between BH-Lon and HGB-mean ozone is consistently linear throughout the study period for each summer month (cf. Figs. 6 and S1).

On the daily scale, however, we found evidence for a threshold of BH-Lon that tends to create conducive or nonconducive conditions for high ozone days over the HGB region. Figure 9a shows the variation of HGB-mean daily ozone anomaly as a function of daily BH-Lon during July 2011, a high ozone month. The daily ozone anomaly is calculated as the difference between daily and 30-day moving average of ozone. The daily data shown in Fig. 9a clearly display two populations, warranting a threshold of BH-Lon to separate them. As a simplified attempt, a linear piecewise fitting was applied to the daily data, using different segmentation points with varying $\mathrm{BH}-\mathrm{L}$ - from 100 to $80^{\circ} \mathrm{W}$ at an interval of $0.5^{\circ}$. The least regression error (sum of the squared errors) was obtained when the segmentation point was set to $90^{\circ} \mathrm{W}$, which represents the threshold of BH-Lon for July 2011. The resulting regression indicates that when the $\mathrm{BH}-\mathrm{Lon}$ is east of $90^{\circ} \mathrm{W}$, the westward extension of $\mathrm{BH}-$ Lon tends to cause a decrease in HGB ozone; the opposite relationship holds when the BH-Lon is west of that threshold (Fig. 9).

To understand the causes of the two regimes, Fig. 9bc compare circulation patterns between two representative days, 3 and 10 July 2011, when the BH-Lon is located to the west and east of its threshold, respectively. The circulation patterns on 10 July (9c), when the BH-Lon was located to the east of $90^{\circ} \mathrm{W}$, are similar to the typical monthly-mean patterns described before: clean maritime air masses flow southeasterly to southeastern Texas along the western edge of the $\mathrm{BH}$, leading to lower surface ozone in HGB (26.4 ppbv on 10 July 2011). On 3 July (9b), there was a high-pressure system over the southeastern US, which appears to be separate from the $\mathrm{BH}$, and in this case the choice of the $1560 \mathrm{gpm}$ isoline may not be appropriate for defining the $\mathrm{BH}$ western edge on a daily scale. According to the wind fields, however, this highpressure system over land likely resulted from the westward extension of the BH to the continental US. The high-pressure system typically brings stagnant weather, high temperatures, and clear skies, which are all favorable meteorological conditions leading to higher ozone on 3 July (42.2 ppbv).

To predict daily ozone on the basis of its statistical relationships with meteorology alone is a challenging task and beyond the scope of the present study. The simple daily anal- 
ysis presented above for the month of July 2011 was intended to demonstrate that the linear relationship between the $\mathrm{BH}$ Lon and HGB-mean ozone on a monthly scale is useful for explaining some portion of HGB ozone variability on a daily scale, but there are certain degrees of nonlinearity in the daily relationship associated with a threshold value of the BH-Lon that separate different circulation regimes, and that threshold value may not be constant for every month. When the BHLon is used to predict the monthly-mean ozone over the HGB area, however, it is not necessary to consider the threshold of BH-Lon since the mean variation of the BH-Lon is a lot smaller on the monthly scale than that on the daily timescale.

\section{Conclusions}

A more than 2-decade (1990-2015) long observational record of MDA8 ozone and meteorology was analyzed to characterize the effects of the $\mathrm{BH}$ circulation patterns on interannual variations of surface ozone in the HGB region during the summer months (June to August). The BH indicators are the longitude of the $\mathrm{BH}$ western edge (BH-Lon) and the pressure-based $\mathrm{BH}$ intensity index (BHI) along its western edge. Statistical relationships between the HGB-mean ozone variability and meteorological predictors, including both large-scale (BH-Lon, BHI) and local-scale ones ( $T, U$, $V$ ), were tested and developed through multiple linear regression (MLR). The best-fit MLR equations select both BHLon and BHI as significant predictors $(p<0.05)$ of interannual variability of the HGB-mean ozone for each month and meridional wind speed $(V)$ as a significant predictor for August only. Temperature or zonal wind speed $(U)$ is not selected as a predictor by the MLR for any of the summer months. The exclusion of temperature in the MLR model is supported by the lack of significant correlations between ozone and temperature over the HGB region on both intraseasonal and interannual timescales. This suggests temperature is not a key driver of summertime ozone variability in the HGB region despite its importance for other regions.

With only three meteorological predictors (BH-Lon, BHI, and $V$ ), the MLR model developed here captures 61-72\% (based on $R^{2}$ ) of the interannual variance of the HGB-mean ozone from June to August. The MLR model developed here also shows a good prediction skill, with the $\mathrm{CV} R^{2}$ higher than 0.45 . The BH-Lon alone explains 38-48\% $(r=0.62-$ 0.69 ) of the year-to-year variability in monthly-mean ozone over HGB during JJA for the period 1990-2015, indicating the dominant role of large-scale circulation patterns controlling ozone variability over this region in summer. Such a high correlation is explained by the mechanism that the western extension of the BH determines the strength of the inflow of maritime air masses with lower ozone background from the Gulf of Mexico to the HGB during summer. This mechanism also applies to other coastal urban regions, such as New Orleans, LA, Mobile, AL, and Pensacola, FL, con- firming the large-scale impact of the BH circulation patterns on surface ozone variability along the Gulf Coast. The linear relationship between the BH-Lon and HGB-mean ozone on a monthly scale is useful for explaining some portion of HGB ozone variability on a daily scale, but there are certain degrees of nonlinearity in the daily relationship associated with a threshold value of the BH-Lon that separates different circulation regimes, and that threshold value may not be constant for every month. The statistical relationship between surface ozone and large-scale circulation patterns derived herein will be useful for distinguishing the role of meteorology versus anthropogenic emissions in controlling the interannual variability of ozone along the Gulf Coast as well as for serving as a benchmark to test the performance of air quality models in representing such distinctions, which will be investigated in future studies.

\section{Data availability}

The data used for the MLR model in this study are available online at https://dataverse.harvard.edu/dataset.xhtml? persistentId=doi:10.7910/DVN/WN42JX.

\section{The Supplement related to this article is available online at doi:10.5194/acp-16-15265-2016-supplement.}

Acknowledgements. This research was supported by the Texas Commission on Environmental Quality (TCEQ; grant no. 58213-34576) and the Texas Air Quality Program (project 14-010). Beixi Jia acknowledges additional funding from the National Key Basic Research Program of China (2013CB956603).

Edited by: N. Lee Ng

Reviewed by: two anonymous referees

\section{References}

Berlin, S. R., Langford, A. O., Estes, M., Dong, M., and Parrish, D. D.: Magnitude, decadal changes, and impact of regional background ozone transported into the greater Houston, Texas area, Environ. Sci. Technol., 47, 13985-13992, 2013.

Camalier, L., Cox, W., and Dolwick, P.: The effects of meteorology on ozone in urban areas and their use in assessing ozone trends, Atmos. Environ., 41, 7127-7137, 2007.

Davis, R. E., Hayden, B. P., Gay, D. A., Phillips, W. L., and Jones, G. V.: The North Atlantic subtropical anticyclone, J. Climate, 10, 728-744, 1997.

Darby, L. S.: Cluster Analysis of Surface Winds in Houston, Texas, and the Impact of Wind Patterns on Ozone, J. Appl. Meteorol., 44, 1788-1806, 2005. 
Day, B. M., Rappenglück, B., Clements, C.B., Tucker, S. C., and Brewer, W. A.: Nocturnal boundary layer characteristics and land breeze development in Houston, Texas during TexAQS II, Atmos. Environ., 44, 4014-4023, doi:10.1016/j.atmosenv.2009.01.031, 2010.

Eder, B. K., Davis, J. M., and Bloomfield, P.: A characterization of the spatiotemporal variability of non-urban ozone concentrations over the eastern United States, Atmos. Environ., 27A, 26452668, 1993.

Fiore, A. M., Jacob, D. J., Mathur, R., and Martin, R. V.: Application of empirical orthogonal functions to evaluate ozone simulations for the eastern United States with regional and global models, J. Geophys. Res., 108, 4431, doi:10.1029/2002JD003151, 2003.

Fu, T. M., Zheng, Y. Q., Paulot, F., Mao, J. Q., and Yantosca, R. M.: Positive but variable sentisitivity of August surface ozone to large-scale warming in the southeast United States, Nature Climate Change, 5, 454-458, doi:10.1038/nclimate2567, 2015.

Haman, C. L., Couzo, E., Flynn, J. H., Vizuete, W., Heffron, B., and Lefer, B. L.: Relationship between boundary layer heights and growth rates with ground-level ozone in Houston, Texas, J. Geophys. Res., 119, 6230-6245, 2014.

Hegarty, J., Mao, H., and Talbot, R.: Synoptic controls on summertime surface ozone in the northeastern United States, J. Geophys. Res., 112, D14306, doi:10.1029/2006JD008170, 2007.

Higgins, R. W., Yao, Y., Yarosh, E. S., Janowiak, J. E., and Mo, K. C.: Influence of the Great Plains low-level jet on summertime precipitation and moisture transport over the central United States, J. Climate, 10, 481-507, 1997.

Hogrefe, C., Biswas, J., Lynn, B., Civerolo, K., Ku, J. Y., Rosenthal, J., Rosenzweig, C., Goldberg, R., and Kinney, P. L.: Simulating regional-scale ozone climatologyover the eastern United States: model evaluation results, Atmos. Environ., 38, 2627-2638, 2004.

Jacob, D. J. and Winner, D. A.: Effect of climate change on air quality, Atmos. Environ., 43, 51-63, 2009.

Kalnay, E., Kanamitsu, M., Kistler, R., Collins, W. M., Deaven, D., Gandin, L., Saha, S., White, G., Woollen, J., Chelliah, M., Wang, J., Leetmas, A., Reynolds, R., Jrnne, R., Kung, E., and Salstein, D.: The NMC/NCAR CDAS/Reanalysis Project, B. Am. Meteorol. Soc., 77, 437-471, 1996.

Kutner, M. H., Nachtsheim, C. J., Neter, J., and Li, W.: Applied Linear Statistical Models. McGraw-Hill/Irwin, New York, NY, USA, 2004.

Langford, A. O., Senff, C. J., Banta, R. M., Hardesty, R. M., Alvarez II, R. J., Sandberg, S. P., and Darby, L. S.: Regional and local background ozone in Houston during Texas Air Quality Study 2006, J. Geophys. Res., 114, D00F12, doi:10.1029/2008JD011687, 2009.

Li, L., Li, W., and Kushnir, Y.: Variation of North Atlantic Subtropical High western ridge and its implication to the Southeastern US summer precipitation, Clim. Dynam., 39, 1401-1412, 2012.

Li, Q., Jacob, D. J., Fairlie, T. D., Liu, H., Yantosca, R. M., and Martin, R. V.: Stratospheric versus pollution influences on ozone at Bermuda: Reconciling past analyses, J. Geophys. Res., 107, doi:10.1029/2002JD002138, 2002.

Li, W., Li, L., Fu, R., Deng, Y., and Wang, H.: Changes to the North Atlantic subtropical high and its role in the intensification of summer rainfall variability in the southeastern United States, J. Climate, 24, 1499-1506, 2011.
Lin, M., Fiore, A. M., Horowitz, L. W., Cooper, O. R., Naik, V., Holloway, J., Johnson, B. J., Middlebrook, A. M., Oltmans, S. J., Pollack, I. B., Ryerson, T. B., Warner, J. X., Wiedinmyer, C., Wilson, J., and Wyman, B.: Transport of Asian ozone pollution into surface air over the western United States in spring, J. Geophys. Res., 117, doi:10.1029/2002JD002138, 2012.

Lin, M., Fiore, A. M., Horowitz, L. W., Langford, A. O., Oltmans, S. J., Tarasick, D., and Rieder, H. E.: Climate variability modulates western US ozone air quality in spring via deep stratospheric intrusions, doi:10.1038/ncomms8105, Nat. Commun., 2015.

Nielsen-Gammon, J., McNeel, T. A., and Li, G.: A conceptual model for eight-hour ozone exceedances in Houston, Texas, Part I: Background ozone levels in eastern Texas, Houston Adv. Res. Cent., Houston, Tex, 2005a.

Nielsen-Gammon, J. W., Tobin, J., and Mcneel, A.: A Conceptual Model for Eight-Hour Ozone Exceedances in Houston, Texas Part II: Eight-Hour Ozone Exceedances in the HoustonGalveston Metropolitan Area, Houston Adv. Res. Cent., Houston, Tex. Houston, Tex, 2005b.

Ngan, F. and Byun, D.: Classification of Weather Patterns and Associated Trajectories of High-Ozone Episodes in the HoustonGalveston-Brazoria Area during the 2005/06 TexAQS-II, J. Appl. Meteorol. Climatol., 50,485-499, 2011.

Ortegren, J. T., Knapp, P. A., Maxwell, J. T., Tyminski, W. P., and Soule, P. T.: Ocean-atmosphere influences on low frequency warm-season drought variability in the Gulf Coast and southeastern United States, J. Appl. Meteor. Climatol., 50, 1177-1186, 2011.

Pakalapati, S., Beaver, S., Romagnoli, J. A., and Palazoglu, A.: Sequencing diurnal air flow patterns for ozone exposure assessment around Houston, Texas, Atmos. Environ., 43, 715-723, 2009.

Pearce J. L., Beringer, J., Nicholls, N., Hyndman, R. J., Tapper, N. J.: Quantifying the influence of local meteorology on air quality using generalized additive models, Atmos. Environ., 45, 13281336, 2011.

Psiloglou, B., Larissi, I., Petrakis, M., Paliatsos, A., Antoniou, A., and Viras, L.: Case Studies on Summertime Measurements of $\mathrm{O}_{3}, \mathrm{NO}_{2}$, and $\mathrm{SO}_{2}$ with a DOAS System in an Urban SemiIndustrial Region in Athens, Greece, Environ. Monit. Assess., 185, 7763-7774, 2013.

Pugliese, S. C., Murphy, J. G., Geddes, J. A., and Wang, J. M.: The impacts of precursor reduction and meteorology on groundlevel ozone in the Greater Toronto Area, Atmos. Chem. Phys., 14, 8197-8207, doi:10.5194/acp-14-8197-2014, 2014.

Rappenglück, B., Perna, R., Zhong, S., and Morris, G. A.: An analysis of the vertical structure of the atmosphere and the upper-level meteorology and their impact on surface ozone levels in Houston, Texas, J. Geophys. Res., 113, D17315, doi:10.1029/2007JD009745, 2008.

Rasmussen, D. J., Fiore, A. M., Naik, V., Horowitz, L. W., McGinnis, S. J., and Schultz, M. G.: Surface ozone-temperature relationships in the eastern US: A monthly climatology for evaluating chemistry-climate models, Atmos. Environ., 47, 142-153, 2012.

Reidmiller, D. R., Fiore, A. M., Jaffe, D. A., Bergmann, D., Cuvelier, C., Dentener, F. J., Duncan, B. N., Folberth, G., Gauss, M., Gong, S., Hess, P., Jonson, J. E., Keating, T., Lupu, A., Marmer, E., Park, R., Schultz, M. G., Shindell, D. T., Szopa, S., Vivanco, M. G., Wild, O., and Zuber, A.: The influence of foreign 
vs. North American emissions on surface ozone in the US, Atmos. Chem. Phys., 9, 5027-5042, doi:10.5194/acp-9-5027-2009, 2009.

Shen, L., Mickley, L. J., and Tai, A. P. K.: Influence of synoptic patterns on surface ozone variability over the eastern United States from 1980 to 2012, Atmos. Chem. Phys., 15, 10925-10938, doi:10.5194/acp-15-10925-2015, 2015.

Stahle, D. W. and Cleaveland, M. K.: Reconstruction and analysis of spring rainfall over the southeastern US for the past 1000 years, B. Am. Meteorol. Soc., 73, 1947-1961, 1992.

Tai, A. P. K., Mickley, L. J., and Jacob, D. J.: Correlations between fine particulate matter (PM2.5) and meteorological variables in the United States: Implications for the sensitivity of PM2.5 to climate change, Atmos. Environ., 44, 3976-3984, 2010.

TCEQ: Texas Commission on Environmental Quality, HoustonGalveston-Brazoria: Current attainment status, available at: http: //www.tceq.texas.gov/airquality/sip/hgb/hgb-status (last access: 16 November 2014), 2012.
Tucker, S. C., Banta, R. M., Langford, A. O., Senff, C. J., Brewer, W. A., Williams, E. J., Lerner, B. M., Osthoff, H., and Hardesty, R. M.: Relationships of coastal nocturnal boundary layer winds and turbulence to Houston ozone concentrations during TexAQS 2006, J. Geophys. Res., 115, D10304, doi:10.1029/2009JD013169, 2010.

Venables, W. N. and Ripley, B. D.: Modern Applied Statistics with S, Springer, New York, NY, USA, 2003.

Zhu, J. and Liang, X.: Impacts of the Bermuda High on Regional Climate and Ozone over the United States, J. Climate, 26, 10181032, 2013. 